\title{
PENDEKATAN VOLUME LALU-LINTAS PADA SETIAP PEREMPATAN DENGAN METODE ESELON BARIS TEREDUKSI
}

\author{
Oleh: Ninik Wahju Hidajati *)
}

\begin{abstract}
Abstrak
Transportasi merupakan bidang yang penting dalam mendukung aktivitas masyarakat. Lancarnya arus lalu lintas sangat diperlukan dan dibutuhkan bagi semua orang. Arus lalu lintas terbentuk dari pergerakan individu pengendara dari kendaraan yang melakukan interaksi antara yang satu dengan yang lainnya pada suatu ruas jalan dan lingkungannya. Arus lalu lintas pada suatu ruas jalan karakteristiknya akan bervariasi baik berdasarkan lokasi maupun waktunya. Volume lalu lintas didefinisikan sebagai jumlah kendaraan yang lewat pada suatu titik di ruas jalan, atau pada suatu lajur selama interval waktu tertentu.

Metode Eselon Baris tereduksi adalah merupakan suatu Metode Matriks dengan menggunakan prinsip sistem persamaan linier. Metode ini dapat digunakan untuk memprediksi volume lalu lintas pada setiap perempatan dari dua kelompok jalan satu-arah yang saling berpotongan pada suatu waktu tertentu
\end{abstract}

Kata Kunci: Volume Lalu Lintas, Perempatan Jalan, Eselon Baris Tereduksi

\section{PENDAHULUAN}

Volume lalu lintas didefinisikan sebagai jumlah kendaraan yang lewat pada suatu titik di ruas jalan. Satuan dari volume secara sederhana adalah "kendaraan", walaupun dapat dinyatakan dengan cara lain yaitu satuan mobil penumpang (smp) tiap satu satuan waktu. Lalu lintas harian ratarata (LHR) sering digunakan sebagai dasar untuk perencanaan jalan raya dan pengamatan secara umum dan terhadap kecenderungan pola perjalanan. Volume harian dinyatakandalam satuan kendaraan perhari atau smp per hari. Proyeksi volume lalu lintas sering didasarkan pada volume harian terukur. LHR diperoleh dengan cara pengamatan volume lalu lintas selama 24 jam pada suatu ruas jalan tertentu, pengamatan ini dilakukan dalam beberapa hari kemudian hasilnya dirata-ratakan sehingga menjadi lalu lintas harian rata-rata.

Untuk memprediksi volume lalu lintas pada setiap perempatan dari dua kelompok jalan satu-arah yang saling berpotongan pada suatu waktu tertentu dapat diketahui dengan metode eselon baris tereduksi dengan catatan diketahi volume kendaraan yang keluar dan masuk dari arah jalan perempatan tersebut.

\section{KAJIAN PUSTAKA}

\section{Sistem Persamaan Linear}

Sistem persamaan linear dengan $m$ persamaan dan $\mathrm{n}$ bilangan tak diketahui ditulis dengan:

$a_{11} x_{11}+a_{12} x_{12}+\ldots+a_{1 n} x_{1 n}=b_{1}$

$$
\begin{aligned}
& a_{21} x_{21}+a_{22} x_{22}+\ldots+a_{2 n} x_{2 n}=b_{2} . \\
& a_{m 1} x_{m 1}+a_{m 2} x_{m 2}+\ldots .+a_{m n} x_{m n}=b_{m}
\end{aligned}
$$
dimana $x_{1}, x_{2}, \ldots, x_{n}$ : bilangan tak diketahui a,b : konstanta

Jika SPL diatas ditulis dalam bentuk matriks, maka:

$$
\left[\begin{array}{cccc}
a_{11} & a_{12} & \ldots & a_{1 n} \\
a_{21} & a_{22} & \ldots & a_{2 n} \\
\ldots & \ldots & \ldots & \ldots \\
a_{m 1} & a_{m 2} & \ldots & a_{m n}
\end{array}\right]\left[\begin{array}{c}
x_{1} \\
x_{2} \\
\ldots \\
x_{n}
\end{array}\right]=\left[\begin{array}{c}
b_{1} \\
b_{2} \\
\ldots \\
b_{m}
\end{array}\right]
$$

Suatu matriks yang berbentuk :

$\left[\begin{array}{ccccc}a_{11} & a_{12} & \ldots & a_{1 n} & b_{1} \\ a_{21} & a_{22} & \ldots & a_{2 n} & b_{2} \\ \ldots & \ldots & \ldots & \ldots & \ldots \\ a_{m 1} & a_{m 2} & \ldots & a_{m n} & b_{m}\end{array}\right]$

dinamakan matrik yang diperbesar (augmented matrix).

Jika $b_{1}=b_{2}=\ldots=b_{m}=0$, maka SPL tersebut disebut sistem persamaan linear homogen.

Jika $b_{1}, b_{2}, \ldots, b_{m}$ tidak semuanya nol, maka SPL tersebut disebut sistem persamaan linear nonhomogen.

Kemungkinan-kemungkinan pemecahan SPL adalah:

*) Dosen Fakultas Teknik Sipil
Universitas Negeri Surabaya 
a. Tidak mempunyai penyelesaian.

b. Mempunyai tepat satu penyelesaian.

c. Mempunyai tak hingga banyaknya penyelesaian.

Sebuah SPL yang tidak mempunyai pemecahan disebut tak konsisten (inconsistent).

Jika ada sekurang-kurangnya satu penyelesaian, maka SPL tersebut konsisten (consistent).

Salah satu metode yang digunakan untuk menyelesaikan suatu SPL adalah eliminas Gauss / Gauss-jordan. Prosedur yang digunakan dalam metode ini adalah dengan mereduksi matriks yang diperbesar menjadi bentuk eselon baris (eliminasi Gauss) atau bentuk eselon baris tereduksi (eliminasi Gauss-Jordan). Proses ini dilakukan dengan menggunakan operasi baris elementer.

Operasi - operasi baris elementer yang dimaksud meliputi:

a. Mengalikan sebuah baris dengan sebuah konstanta yang tidak sama dengan nol.

b. Menukarkan letak 2 baris.

c. Menambahkan perkalian dari satu baris pada baris yang lain.

2. Eliminasi Gauss/Gauss-Jourdan Untuk Menyelesaikan SPL Nonhomogen

Contoh 1 :

$$
\begin{gathered}
x+y+2 z=9 \\
2 x+4 y-3 z=1 \\
3 x+6 y-5 z=0
\end{gathered}
$$

matriks yang diperbesar untuk system tersebut adalah:

$$
\left[\begin{array}{cccc}
1 & 1 & 2 & 9 \\
2 & 4 & -3 & 1 \\
3 & 6 & -5 & 0
\end{array}\right]
$$

Jika system tersebut diselesaikan dengan menggunakan eliminasi Gauss, maka langkah-langkahnya adalah sebagai berikut: langkah 1: baris 2 dikurangi 2 kali baris 1

$$
\left[\begin{array}{cccc}
1 & 1 & 2 & 9 \\
0 & 2 & -7 & -17 \\
3 & 6 & -5 & 0
\end{array}\right]
$$

langkah 2: baris 3 dikurangi 3 kali baris 1

$$
\left[\begin{array}{cccc}
1 & 1 & 2 & 9 \\
0 & 2 & -7 & -17 \\
0 & 3 & -11 & -27
\end{array}\right]
$$

langkah 3: baris 2 dikali $1 / 2$

$$
\left[\begin{array}{cccc}
1 & 1 & 2 & 9 \\
0 & 2 & -\frac{7}{2} & -\frac{17}{2} \\
0 & 3 & -11 & -27
\end{array}\right]
$$

langkah 4: baris 3 dikurangi 3 kali baris 2

$$
\left[\begin{array}{cccc}
1 & 1 & 2 & 9 \\
0 & 2 & -\frac{7}{2} & -\frac{17}{2} \\
0 & 0 & -\frac{1}{2} & -\frac{3}{2}
\end{array}\right]
$$

langkah 5: baris 3 dikalikan -2

$$
\left[\begin{array}{cccc}
1 & 1 & 2 & 9 \\
0 & 1 & -\frac{7}{2} & -\frac{17}{2} \\
0 & 0 & 1 & 3
\end{array}\right]
$$

matriks diatas adalah bentuk eselon baris

Langkah 6: Tentukan system yang bersesuaian dengan matriks pada langkah 5

$$
\begin{aligned}
x+y+2 z & =9 \\
y-7 / 2 z & =-17 / 2 \\
z & =3
\end{aligned}
$$

Langkah 7: Gunakan subtitusi balik untuk mencari penyelesaian system pada langkah 6, didapat:

$x=1, y=2, z=3$

Contoh 2 :

Selesaikan dengan menggunakan eliminasi Gauss-Jordan

$$
\begin{array}{r}
x_{1}+3 x_{2}-2 x_{3}+2 x_{5}=0 \\
2 x_{1}+6 x_{2}-5 x_{3}-2 x_{4}+4 x_{5}-3 x_{6}=-1 \\
5 x_{3}+10 x_{4}+15 x_{6}=5 \\
2 x_{1}+6 x_{2}+8 x_{4}+4 x_{5}+18 x_{6}=6
\end{array}
$$

matriks yang diperbesar untuk system tersebut adalah:

$$
\begin{aligned}
& \mathrm{B}_{2}-2 \mathrm{~B}_{1} \\
& \mathrm{~B}_{4}-2 \mathrm{~B}_{1}
\end{aligned} \quad\left[\begin{array}{ccccccc}
1 & 3 & -2 & 0 & 2 & 0 & 0 \\
2 & 6 & -5 & -2 & 4 & -3 & -1 \\
0 & 0 & 5 & 10 & 0 & 15 & 5 \\
2 & 6 & 0 & 8 & 4 & 18 & 6
\end{array}\right]
$$


Operasi baris elementer untuk mengubah matriks diatas menjadi bentuk eselon baris tereduksi adalah sbb:

$$
\begin{aligned}
& \begin{array}{l}
(-1) \mathrm{B}_{2} \\
\mathrm{~B}_{3}+5 \mathrm{~B}_{2} \\
\mathrm{~B}_{4}+4 \mathrm{~B}_{2}
\end{array} \quad\left[\begin{array}{ccccccc}
1 & 3 & -2 & 0 & 2 & 0 & 0 \\
0 & 0 & -1 & -2 & 0 & -3 & -1 \\
0 & 0 & 5 & 10 & 0 & 15 & 5 \\
0 & 0 & 4 & 8 & 0 & 18 & 6
\end{array}\right] \\
& \mathrm{B}_{3} \Leftrightarrow \mathrm{B}_{4} \quad\left[\begin{array}{ccccccc}
1 & 3 & -2 & 0 & 2 & 0 & 0 \\
0 & 0 & 1 & 2 & 0 & 3 & 1 \\
0 & 0 & 0 & 0 & 0 & 0 & 0 \\
0 & 0 & 0 & 0 & 0 & 6 & 2
\end{array}\right] \\
& \left(\frac{1}{6}\right) B_{3} \quad\left[\begin{array}{ccccccc}
1 & 3 & -2 & 0 & 2 & 0 & 0 \\
0 & 0 & 1 & 2 & 0 & 3 & 1 \\
0 & 0 & 0 & 0 & 0 & 1 & \frac{1}{3} \\
0 & 0 & 0 & 0 & 0 & 0 & 0
\end{array}\right] \\
& \mathrm{B}_{1}+2 \mathrm{~B}_{2}-3 \mathrm{~B}_{3} \quad\left[\begin{array}{ccccccc}
1 & 3 & 0 & 4 & 2 & 0 & 0 \\
0 & 0 & 1 & 2 & 0 & 0 & 0 \\
0 & 0 & 0 & 0 & 0 & 1 & \frac{1}{3} \\
0 & 0 & 0 & 0 & 0 & 0 & 0
\end{array}\right]
\end{aligned}
$$

Sistem persamaan yang bersesuaian adalah:

$$
\begin{aligned}
x_{1}+3 x_{2}+4 x_{4}+2 x_{5} & =0 \\
x_{3}+2 x_{4} & =0 \\
x_{6} & =1 / 3
\end{aligned}
$$

didapat $x_{1}=-3 x_{2}-4 x_{4}-2 x_{5} \quad x_{3}=-2 x_{4} \quad x_{6}=$ $1 / 3$

Misal $x_{2}=r, \quad x_{4}=s, \quad x_{5}=t, \quad$ maka didapat penyelesaian:

$$
\begin{aligned}
& x_{1}=-3 r-4 s-2 t, \quad x_{2}=r, \quad x_{3}=-2 s, \quad x_{4} \\
& =s, \quad x_{5}=t, x_{6}=1 / 3
\end{aligned}
$$

\section{Sistem Persamaan Linear Homogen}

\section{Bentuk umum:}

$$
\begin{aligned}
& a_{11} x_{11}+a_{12} x_{12}+\ldots+a_{1 n} x_{1 n}=0 \\
& a_{21} x_{21}+a_{22} x_{22}+\ldots+a_{2 n} x_{2 n}=0 \\
& a_{m 1} x_{m 1}+a_{m 2} x_{m 2}+\ldots+a_{m n} x_{m n}=0
\end{aligned}
$$

Setiap SPL homogen adalah sistem yang konsisten, karena SPL homogen selalu mempunyai paling sedikit satu penyelesaian yaitu $x_{1}=0, x_{2}=0, \ldots, x_{n}=0$. Pemecahan tersebut disebut pemecahan trivial (trivial solution). Jika ada pemecahan lain, maka pemecahan tersebut dinamakan pemecahan taktrivial (nontrivial solution). Untuk SPL homogen, maka salah satu dari pernyataan berikut benar : a. Sistem tersebut hanya mempunyai penyelesaian trivial.

b. Sistem tersebut mempunyai tak hingga banyaknya penyelesaian taktrivial sebagai tambahan terhadap pemecahan trivial tersebut.

Contoh: Eliminasi Gauss-Jordan untuk menyelesaikan SPL homogen

$$
\begin{array}{r}
2 x_{1}+2 x_{2}-x_{3}+x_{5}=0 \\
-x_{1}-x_{2}+2 x_{3}-3 x_{4}+x_{5}=0 \\
x_{1}+x_{2}-2 x_{3}-x_{5}=0 \\
x_{3}+x_{4}+x_{5}=0
\end{array}
$$

matriks yang diperbesar untuk system tersebut adalah:

$$
\left[\begin{array}{cccccc}
2 & 2 & -1 & 0 & 1 & 0 \\
-1 & -1 & 2 & -3 & 1 & 0 \\
1 & 1 & -2 & 0 & -1 & 0 \\
0 & 0 & 1 & 1 & 1 & 0
\end{array}\right]
$$

Operasi baris elementer untuk mengubah matriks diatas menjadi bentuk eselon baris tereduksi adalah sbb:

$$
\begin{aligned}
& \mathrm{B}_{2}+\mathrm{B}_{3}+\mathrm{B}_{2}\left[\begin{array}{cccccc}
2 & 2 & -1 & 0 & 1 & 0 \\
0 & 0 & 0 & -3 & 0 & 0 \\
0 & 0 & 0 & -3 & 0 & 0 \\
0 & 0 & 1 & 1 & 1 & 0
\end{array}\right] \\
& B_{3}-B_{2}\left[\begin{array}{cccccc}
2 & 2 & -1 & 0 & 1 & 0 \\
0 & 0 & 0 & -3 & 0 & 0 \\
0 & 0 & 0 & 0 & 0 & 0 \\
0 & 0 & 1 & 1 & 1 & 0
\end{array}\right] \\
& \begin{array}{l}
\mathrm{B}_{3} \Leftrightarrow \mathrm{B}_{4} \\
\mathrm{~B}_{4} \Leftrightarrow \mathrm{B}_{2} \\
\mathrm{~B}_{2} \Leftrightarrow \mathrm{B}_{3}
\end{array}\left[\begin{array}{cccccc}
2 & 2 & -1 & 0 & 1 & 0 \\
0 & 0 & 1 & 1 & 1 & 0 \\
0 & 0 & 0 & 1 & 0 & 0 \\
0 & 0 & 0 & 1 & 0 & 0
\end{array}\right] \\
& \mathrm{B}_{3}\left(-\frac{1}{3}\right) \mathrm{B}_{3}\left[\begin{array}{cccccc}
2 & 2 & -1 & 0 & 1 & 0 \\
0 & 0 & 1 & 1 & 1 & 0 \\
0 & 0 & 0 & -3 & 0 & 0 \\
0 & 0 & 0 & 1 & 1 & 0
\end{array}\right] \\
& \begin{array}{c}
B_{2}-B_{3} \\
B_{1}+B_{2}
\end{array}\left[\begin{array}{llllll}
2 & 2 & 0 & 0 & 2 & 0 \\
0 & 0 & 1 & 0 & 1 & 0 \\
0 & 0 & 0 & 1 & 0 & 0 \\
0 & 0 & 0 & 0 & 0 & 0
\end{array}\right]
\end{aligned}
$$




$$
B_{1}\left(\frac{1}{2}\right) B \quad\left[\begin{array}{cccccc}
1 & 1 & 0 & 0 & 1 & 0 \\
0 & 0 & 1 & 0 & 1 & 0 \\
0 & 0 & 0 & 1 & 0 & 0 \\
0 & 0 & 0 & 0 & 0 & 0
\end{array}\right]
$$

SPL yang bersesuaian adalah:

$$
\begin{array}{rrrr}
x_{1}+x_{2} & & +x_{5} & =0 \\
& x_{3} & & \\
& & x_{5} & =0 \\
& x_{4} & =0
\end{array}
$$

penyelesaian untuk SPL diatas adalah:

$$
\begin{aligned}
& x_{1}=-x_{2}-x_{5} \\
& x_{3}=-x_{5} \\
& x_{4}=0
\end{aligned}
$$

Kesimpulan :

jika $x_{2}=s, x_{5}=t$ maka: $x_{1}=-s-t, x_{3}=s, x_{4}=$ 0

\section{Karakteristik Volume Lalu Lintas}

Volume lalu lintas pada dasarnya terbagi atas waktu dan ruang, yang biasanya lebih difokuskan kepada volume jam puncak seperti jam sibuk kerja, komuter dan perjalanan yang lain. Permintaan lalu lintas dapat bervariasi berdasarkan musim dalam setahun, bulanan dalam setahun, hari dalam sebulan, hari dalam seminggu, maupun jamjaman dalam sehari. Variasi volume lalu lintas jam-jaman dalam sehari juga mengalami fluktusi dengan karakteristik pengguna jalan. Hal ini terjadi terkait dengan berangkat aktivitas, saat beraktivitas maupun pulang aktivitas. Aktivitas bisa berupa kerja kantor, pendidikan, perdagangan, sosial dan lain sebagainya.

\section{PERMASALAHAN}

Di bagian salah satu kota yang ramai dari suatu kota, dua kelompok jalan satu-arah berpotongan seperti pada Gambar 1. Rata-rata jam dari volume lalu-lintas yang memasuki dan meninggalkan bagian ini selama jam sibuk dititunjukkan dalam gambar 1.

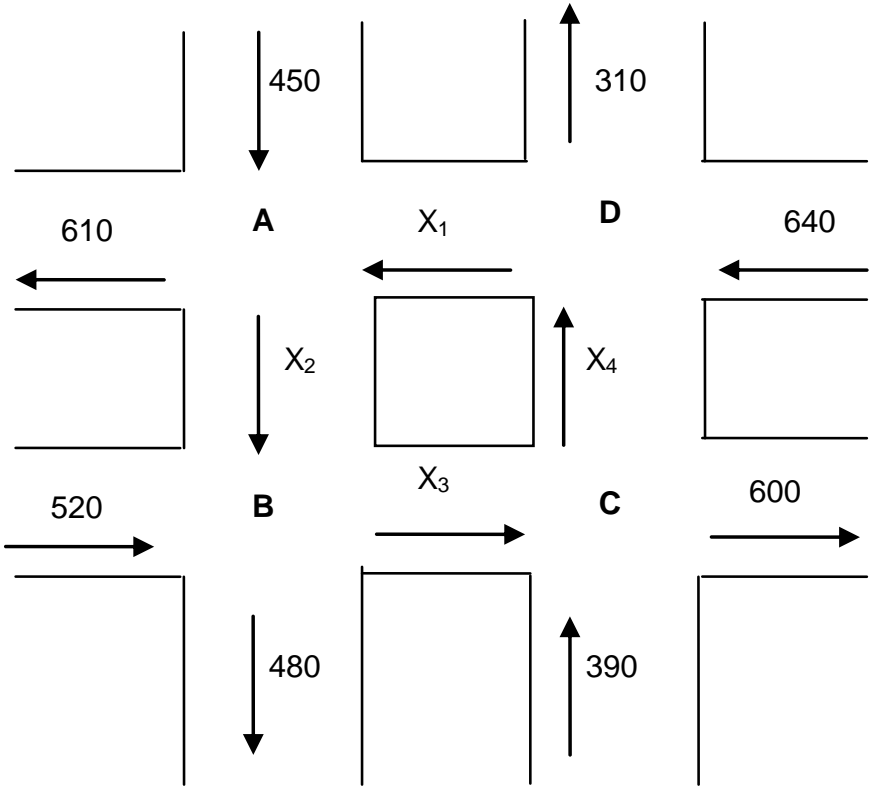

Gambar 1. Volume Lalu Lintas pada setiap perempatan dari dua kelompok jalan satu-arah yang saling berpotongan pada suatu waktu tertentu

Tentukan banyaknya lalu lintas antara pada setiap perempatan ( jumlah kendaraan yang terdapat pada jalur $\mathrm{x}_{1}, \mathrm{x}_{2}, \mathrm{x}_{3}, \mathrm{x}_{4}$.

Petunjuk : dengan menerjemahkan gambar tersebut ke SPL, yaitu jumlah volume kendaraan yang masuk sama dengan volume kendaraan yang keluar.

\section{PEMBAHASAN}

Pada setiap perempatan banyaknya kendaraan yang masuk harus sama dengan banyaknya yang keluar. Sebagai contoh, pada perempatan $\mathrm{A}$, banyaknya mobil yang masuk adalah $x_{1}+450=x_{2}+610$ (jumlah kendaraan yang keluar) demikian seterusnya. Sehingga dapat disusun persamaan-persamaan :

$\begin{array}{lll}\mathrm{x}_{1}+450 & =\mathrm{x}_{2}+610 & (\text { perempatan } A) \\ \mathrm{x}_{2}+520 & =\mathrm{x}_{3}+480 & (\text { perempatan } B) \\ \mathrm{x}_{3}+390 & =\mathrm{x}_{4}+600 & (\text { perempatan } C) \\ \mathrm{x}_{4}+640 & =\mathrm{x}_{1}+310 & (\text { perempatan } D)\end{array}$

Ke - empat persamaan tersebut bisa disusun menjadi :

$$
\begin{array}{rlr}
\mathrm{x}_{1}-\mathrm{x}_{2} & =160 \quad(\text { perempatan } A) \\
\mathrm{x}_{2}-\mathrm{x}_{3} & =-40 \quad(\text { perempatan } B) \\
\mathrm{x}_{3}-\mathrm{x}_{4} & =210 \quad(\text { perempatan } C) \\
\mathrm{x}_{1}+\mathrm{x}_{4} & =-330 \quad(\text { perempatan } D)
\end{array}
$$


Dari ke-empat persamaan tersebut disusun matriks diperbesar, yaitu :

$$
\begin{aligned}
& {\left[\begin{array}{cccccc}
1 & -1 & 0 & 0 & \rightarrow & 160 \\
0 & 1 & -1 & 0 & \rightarrow & -40 \\
0 & 0 & 1 & -1 & \rightarrow & 210 \\
-1 & 0 & 0 & 1 & \rightarrow & -330
\end{array}\right]} \\
& -1 \mathrm{~B}_{1}+\mathrm{B}_{4} \quad\left[\begin{array}{cccccc}
1 & -1 & 0 & 0 & \rightarrow & 160 \\
0 & 1 & -1 & 0 & \rightarrow & -40 \\
0 & 0 & 1 & -1 & \rightarrow & 210 \\
0 & -1 & 0 & 1 & \rightarrow & -170
\end{array}\right] \\
& \begin{array}{r}
1 \mathrm{~B}_{2}+\mathrm{B}_{1} \\
-1 \mathrm{~B}_{2}+\mathrm{B}_{4}
\end{array} \quad\left[\begin{array}{cccccc}
1 & 0 & -1 & 0 & \rightarrow & 120 \\
0 & 1 & -1 & 0 & \rightarrow & -40 \\
0 & 0 & 1 & -1 & \rightarrow & 210 \\
0 & 0 & -1 & 1 & \rightarrow & -210
\end{array}\right] \\
& \begin{array}{c}
1 \mathrm{~B}_{3}+\mathrm{B}_{1} \\
1 \mathrm{~B}_{3}+\mathrm{B}_{2} \\
1 \mathrm{~B}_{3}+\mathrm{B}_{4}
\end{array} \quad\left[\begin{array}{cccccc}
1 & 0 & 0 & -1 & \rightarrow & 330 \\
0 & 1 & 0 & -1 & \rightarrow & 170 \\
0 & 0 & 1 & -1 & \rightarrow & 210 \\
0 & 0 & 0 & 0 & \rightarrow & 0
\end{array}\right]
\end{aligned}
$$

Sistem ini adalah konsisten dan karena terdapat satu peubah bebas, maka terdapat banyak penyelesaian yang mungkin. Diagram arus lalu lintas di atas tidak memberi informasi yang cukup untuk menentukan $x_{1}, x_{2}, x_{3}, x_{4}$ secara tunggal. Jika banyaknya lalu lintas diketahui antara setiap pasang perempatan, maka banyaknya lalu-lintas di jalan raya selebihnya dengan mudah dapat dihitung.

Sebagai contoh, jika banyaknya lalu-lintas antara perempatan $\mathrm{C}$ dan $\mathrm{D}$ memiliki ratarata 200 kendaraan per jam, maka $x_{4}=200$, sehingga $x_{1}, x_{2}, x_{3}$ dapat dicari :

$$
\begin{aligned}
\mathrm{x}_{3}-\mathrm{x}_{4}=210 \rightarrow \mathrm{x}_{3} & =210+\mathrm{x}_{4} \\
& =210+200 \\
& =410 \\
\mathrm{x}_{2}-\mathrm{x}_{4}=170 \rightarrow \mathrm{x}_{2} & =170+\mathrm{x}_{4}
\end{aligned}
$$

$$
\begin{aligned}
& =170+200 \\
& =370 \\
x_{1}-x_{4}=330 \rightarrow \quad \rightarrow \quad x_{1} & =330+x_{4} \\
& =330+200 \\
& =530
\end{aligned}
$$

Artinya bahwa pada kasus diatas, dengan volume kendaraan yang tidak menentu, volume kendaraan pada dua kelompok jalan satu arah berpotongan dapat diprediksi. Dimana volume kendaraan pada jalur $x_{1}, x_{2}, x_{3}$ tergantung pada volume di jalur $\mathrm{x}_{4}$.

Artinya apabila jumlah kendaraan di jalur $x_{4}$ berjumlah 200 unit kendaraan, maka pada jalur $x_{1}$ berjumlah 530 unit kendaraan, $x_{2}$ berjumlah 370 unit kendaraan dan $x_{3}$ berjumlah 410 unit kendaraan

\section{SIMPULAN}

Berdasarkan hasil kajian pendekatan volume kendaraan pada perempatan jalan dengan metode eselon baris tereduksi dapat disimpulkan sebagai berikut :

4. Untuk mengetahui volume pada setiap perempatan dari dua kelompok jalan satu-arah yang saling berpotongan pada suatu waktu tertentu dapat diprediksi dengan metode eselon baris tereduksi.

5. Kemungkinan hasil yang didapatkan ada dua ( sesuai kemungkinan pemecahan dalam SPL ), yaitu :

a. Mempunyai penyelesaian satu nilai yang pasti

b. Mempunyai banyak penyelesaian, dimana besarnya volume kendaraan pada jalur-jalurnya tergantung volume lalu-lintas yang terjadi pada salah satu jalur di perempatan tersebut.

\section{SARAN}

Penyelesaian dengan cara matrik ini, khususnya metode eselon baris tereduksi dapat dikerjakan dengan lebih cepat dan tepat apabila menggunakan program matlab 


\section{DAFTAR PUSTAKA}

Anton, H., 1994, Aljabar Linear Elementer, Jakarta : Penerbit Erlangga

Cullen, Charles G, 1993, Aljabar Linear dengan Penerapannya, Jakarta : Penerbit PT. Gramedia Pustaka Umum

Diktat Kuliah : Rekayasa Lalu Lintas, Karakteristik Lalu Lintas, teknik Sipil Universitas widyagama Malang.

http://puslit2.petra.ac.id/ejournal/index.php/its/article/download/17191/17130,

Kemacetan berhubungan Dengan Volume Lalu Lintas yang Melintas Pada Suatu Ruas Jalan, tgl down load 12 Juli 2010

Leon, Steven J, 2001, Aljabar Linear dan Aplikasinya, Jakarta : Penerbit Erlangga 